material from Ungava until I began analysis of a rather large pre-Dorset sample gathered in 1959 from the Arnapik site, on Mansel Island, near the western approach to Hudson Strait.

The Arnapik site, a pure pre-Dorset assemblage, was occupied perhaps in the last half of the second millennium B.C. Approximately 1800 artifacts were collected from its bare gravel surface. Of these, 313 were classed as blades and microblades; dependable width measurements could be taken on 293.

Obviously this number allowed a test of width as a criterion for distinguishing blades from microblades. Maximum widths were taken to the nearest millimeter, at right angles to the long axis of the specimen, and always below the bulb of percussion. Sometimes the margins of a specimen are convex adjacent to that feature. The frequencies of widths were plotted on a graph (Fig. 1) which has a bimodal curve. These data show a trough (a relative or local minimum point occurrring between the two modes) at a width of $11 \mathrm{~mm}$., so close to the Danish figure that the latter can hardly have been chosen in a purely arbitrary fashion. Consequently, for the Arnapik sample, specimens over 11 $\mathrm{mm}$. in maximum width are classed as blades; any $11 \mathrm{~mm}$. or less, are classed as microblades. The ratio is approximately 9:11. The 162 Arnapik microblades range in width from 3 to $11 \mathrm{~mm}$., averaging $7.8 \mathrm{~mm}$. The 131 blades vary between 12 and $27 \mathrm{~mm}$. in width, with an average of $14.9 \mathrm{~mm}$. Parenthetically, available measures show microblades to range between 15 and $43 \mathrm{~mm}$. in length, averaging $32 \mathrm{~mm}$. but the blades, ranging from 26 to $57 \mathrm{~mm}$., have an average length of $39 \mathrm{~mm}$. Although conical, cubical, tubular, and tongue-shaped (a single dubious identification) polyhedral cores occurred on the Arnapik site, they do not allow a correlation between core types and the blade-microblade distinction offered here.

This is not to imply that an $11 \mathrm{~mm}$. width is the only or absolute criterion distinguishing blades from microblades, in the Arctic or even in pre-Dorset assemblages. It should, however, provide a usable point of comparison. Two quite evident avenues of comparison come to mind. First, holding to the $11 \mathrm{~mm}$. mark, what is the blade-microblade ratio in other samples? How does this ratio vary in time and space? Second, does the trough (or local minimum) show meaningful variation in those respects? The term "blade" carries two general meanings in American Arctic archaeology; that used above is the more specialized. The second and more mundane meaning of the term refers to a cutting edge as with harpoon, lance, adz, and knife blades. Both meanings occur repeatedly in Arctic literature but the context does not always provide the intended meaning. For example, retouched blade, blade fragment, and bifacial blade are often confusing phrases. Therefore, for the sake of clarity Arctic prehistorians might well restrict the term "blade" to its second, more common meaning. A new term could then be introduced for the more robust brother of the microblade; perhaps the term "macroblade" would be acceptable.

National Museum of Canada Ottawa, Ont. July, 1961

\title{
ANNOUNCEMENT OF THE ANNUAL MEETING
}

The 27th Annual Meeting of the Society for American Archaeology will be held in Tucson, Arizona, May 3, 4, 5, 1962. The University of Arizona is the host institution; all formal sessions of the meeting will be held on the campus. The Pioneer Hotel will serve as headquarters.

The program will consist of symposia on Hohokam archaeology (plenary session), history of metallurgy in the New World, problems in the administration of emergency archaeology, and tree-ring dating (sponsored by the Tree-Ring Society); areal and topical sessions of contributed papers; and field trips of one-day duration to Ventana Cave, Snaketown, Casa Grande, and other archaeological sites near Tucson. William W. Wasley is Program Chairman; Raymond H. Thompson, Chairman of the Local Arrangements Committee.

The 28th Annual Meeting will be held at the University of Colorado, Boulder, Colorado, May, 1963. 